\title{
(AUTO)RETRATOS POÉtICOS NA OBRA DE HERBERTO HELDER
}

\section{POETIC (SELF)PORTRAITS IN HERBERTO HELDER' WORK}

DANIEL RODRIGUES*

daniel.rodrigues@univ-bpclermont.fr

O nosso objetivo é analisar uma série de retratos poéticos esboçados na obra do poeta português Herberto Helder. Partindo da importância do gênero artístico frequentemente evocado na obra, tentaremos mostrar como o retrato ultrapassa as referências claras ao gênero para configurar uma das práticas literárias fundadoras da obra herbertiana. Propomos considerar a obra como um corpus constituído por uma montagem temporal onde o retrato surge como figurações do rosto autoral.

Palavras-Chave: Herberto Helder; poesia; retrato; montagem; narração.

Our intention is to analyze a series of poetic portraits sketched in the work of Portuguese poet Herberto Helder. Starting from the importance of the artistic genre often evoked in the work, we will try to show how the portrait goes beyond the clear references to the genre to configure one of the founding literary practices of the herbertian work. We propose to consider the work as a corpus constituted by a temporal assembly where the portrait appears as figurations of the authorial face.

Keywords: Herberto Helder; poetry; portrait; edition; narrativity.

DOI: https://doi.org/10.21814/2i.2123

\footnotetext{
* Maître de conférences na Universidade Clermont Auvergne e membro do Laboratório CELIS (Centre de Recherches sur les Littératures et la Sociopoétique), Clermont-Ferrand, França.
} 


\section{Introdução}

Parece evidente notar a singularidade do retrato na obra de H. Helder, bastando lembrar títulos como Retrato em Movimento (1967), Apresentação do Rosto (1968) ou ainda Photomaton \& Vox (1979). Todavia, os retratos helderianos revelam a tentativa de restituir o sujeito no fluxo temporal, inserindo-o numa série de metamorfoses imagéticas e metafóricas. Como? Tentaremos aqui analisar duas técnicas evocadas pelo poeta: a narração e a montagem.

A obra do poeta Herberto Helder é marcada pela circularidade de temas, versos e imagens que levaram a crítica tanto a defender a sua textualidade ${ }^{1}$ como a figura de um "sujeito forte". ${ }^{2} \mathrm{O}$ certo é que a prática intensa da reescrita helderiana e a recorrência de certas imagens reforçam a afirmação de uma voz autoral que, poema após poema, delimitam uma "verdade biográfica" (Helder, 2014, p. 626). Contudo, a vontade expressa de se inscrever numa vida "compacta e limpa" (Helder, 2014, p. 626) surge quase sempre como a expressão de um desejo não alcançado. A impossibilidade de uma vida "[g]ramatical" (Helder, 2014, p. 626) é expressa tanto de maneira clara, "queria fecharme inteiro num poema" (Helder, 2014, p. 730), como através da impossibilidade posto que a memória é sempre fadada ao esquecimento, "os capítulos maiores da minha vida, suas músicas e palavras,/ esqueci-os todos:" (Helder, 2014, p. 702). Assim, a biografia helderiana se apresenta de forma oblíqua e fragmentada, como momentos de "idade[s] de poesia" (Helder, 2014, p. 102). Ela pode, por conseguinte, ser lida como uma série de (auto)retratos poéticos construídos na intersecção da escrita e de outras técnicas, como o cinema, a fotografia, a pintura e a escultura.

\section{Narração}

A narratividade em Herberto Helder aparece ligada ao retrato ainda na primeira recolha de poesia publicada em 1961, A Colher na Boca. O poema que encerra o volume intitulase "Narração de um homem em maio", e nele lemos: "Estou estendido como autor na ligeira/ palavra que a noite molha (...)", (Helder, 2014, p. 99). A sobreposição do corpo do sujeito com a voz autoral faz com que estas duas instâncias apareçam enquanto duplos, retratista e retratado. Esta fragmentação traz à tona um narração entre dois momentos na formação do poeta, um sujeito inserido em paisagens primaveris, atento "ao livro que arde nos ossos" (Helder, 2014, p. 99) e outro, evocado no presente, "parado no movimento de uma vida" (Helder, 2014, p. 102). Notamos assim que a narratividade é articulada pela alternância dos sujeitos e dos verbos no passado e no presente, criando uma imagem diacrônica, superposta, que não deixa de lembrar a ars memoriae. A relação entre o espaço primaveril e a memória entretanto não se relaciona, todavia, claramente com imagens, sendo o poema marcado pela musicalidade e pelo canto.

Já em $A$ faca não corta o fogo, a narratividade liga-se com a técnica da pintura, pois o espaço sugere um atelier onde a questão da luz, da origem desta até o seu jogo de refração no "décimo quarto piso da luz e, no tôpo, a tecnicamente definida, lucarna,/ que

\footnotetext{
${ }^{1}$ Para Silvina Rodrigues Lopes, a poesia helderiana traça “diálogos (de não-sujeitos)" (Lopes, 2003, p. 14).

${ }^{2}$ Luis Maffei afirmará, por sua vez: "sujeito (...) forte se vê ameaçado. Ou incompleto" (Maffei, 2009, p. 115).
} 
é por onde se faz com que a luz se faça" (Helder, 2014, p. 549). Aqui, a narração surge através da introdução da confissão, já que encontramos um velho pintor, ou simples voyeur, e o seu desejo sexual pela jovem "catorzinha":

aos vinte ou quarenta anos os poemas de amor têm uma força directa, e alguém entre as obscuras hierarquias apodera-se dessa força, mas aos setenta e sete é tudo obsceno,

não só o amor, poema, desamor, mas setenta e sete em si mesmos

anos horrendos,

nudez horrenda,

vê-se o halo da aparecida, catorzinha, (...) (Helder, 2014, p. 548)

Na primeira estrofe, o sujeito expõe a sua estratégia de defesa, deslocando a natureza do crime, que passa de pedofilia à aparição do sublime. Um pouco depois, face ao reconhecimento do crime, o sujeito aceita a sua condenação:

e sim pedofilia, crime gravíssimo

¿mas como crime, pedofilia, se a beleza, essa, desencontrada

nas contas, é que é abusiva?

e se me é defêsa, e terrível como um exército que avança, eu, setenta e sete de morte e teoria:

o acesso à música, o rude júbilo, o poema destrutivo, amo-te

com assombro,

eu que nunca te falei de falta de sentido,

porque o único sentido, digo-te agora, é a beleza mesmo,

a tua, a proibida, entrar por mim adentro

e fazer uma grande luz agreste, de corpo e encontro, de ver a Deus se houvesse, luz terrestre, em mim, bicho vil e vicioso. (Helder, 2014, p. 549).

Este eu, que se afirma e se condena ao mesmo tempo, ${ }^{3}$ traz à tona um dos traços característicos da poesia helderiana, isto é, a tensão entre um sujeito racional e a animalização deste, pois ele encontra-se inserido no "poema destrutivo", força superior ao divino que, ao enunciar o retrato do sujeito, pressupõe o seu desaparecimento ou a sua morte.

Em "Doença de pele", conto de Os Passos em Volta, a condenação relaciona-se igualmente à metamorfose do homem racional em um retrato bestial:

Um dia comprei uma garrafa de aguardente e embebedei-me no quarto. Despi-me todo: era branco e repugnante. Tinha-me caído as sobrancelhas e os pêlos do púbis e, por toda a parte, a carne tornara-se inconsistente. E vi então em mim, no meio da bebedeira, certa beleza tenebrosa, uma danação pela qual me apaixonei. Adormeci nu sobre o assoalho chorando de áspera e árida alegria. (Helder, 2001, p. 81)

Podemos aqui nos questionar sobre a validade do gênero retrato quando se trata de um personagem, posto que, com afirma Tzvetan Todorov, o retrato deve poder "ser confrontado a um modelo que existiu realmente" (Todorov, 2004, p. 16). Entretanto, com o jogo de autorreferência helderiano, os personagens dos contos sempre se relacionam com imagens, reais ou mentais, do eu poético dos textos dos Poemas Completos. A effictio, isto é, os traços físicos, passa então a representar um ethos associado a crueldade e a ferocidade do autor. A hibridização genérica helderiana foge assim a definição estrita do autorretrato estabelecida por Michel Beaujour que, ao definir o gênero autorretrato

\footnotetext{
3 Analisando a confissão na época romana, Yan Thomas afirma: “Avouer (...) c'est en quelque sorte s'instituer comme juge de soi-même et se condamner" (Thomas, 2001, p. 17).

4 “(...) une image qu'on voit en elle-même mais qui se laisse aussi confronter à un modèle réellement existant. "[Tradução nossa.]
} 
literário, tenta isolá-lo da autobiografia, e da confissão, justamente pela ausência da narratividade.

Outra técnica para reintroduzir a narratividade nos seus retratos literários é a fragmentação do texto e a inserção de parênteses e/ ou travessões. Num texto republicado em em minúsculas, e inicialmente no Notícias em Angola, em 1971, Herberto Helder retraça a biografia do cantor brasileiro Nelson Ned. O poeta-jornalista não se furta em narrar a vida do "homem com um metro de altura". Ele parte da sua infância difícil no interior do estado de Minas Gerais, passa pelas dificuldades do início da carreira para chegar a glória do cantor: "Não é por piedade que me aplaudem" (Helder, 2018, p. 83), afirma Nelson Ned. Contudo, o texto é atravessado por figurações, aparições, que fragmentam a narrativa, aproximando-a do retrato poético. Por exemplo no texto escrito entre parênteses já no quarto parágrafo:

(De repente, vejo que o rosto do homem, diante de mim, conserva uma espécie de febre, de faminta inocência, vindas do fundo dos anos e dos confins de Minas Gerais. Nem o êxito e o dinheiro aplacaram a antiga inquietação, a fome velha. $\mathrm{O}$ olhar inteligente não sorri nunca. É dos olhares mais implacavelmente destituídos de alegria que vi na minha vida (...)) (Helder, 2018, p. 82).

A aparição do rosto ativa traços de uma criança que evoca outro personagem de $O s$ Passos em Volta, a criança do conto "Coisas eléctricas na Escócia". Neste texto a narração se interrompe com a introdução de verbos no presente: "Mas as crianças perigosas são tristes, como os deuses perigosos. Cria-se à sua volta um campo de interdição: a glória faz-se de distância e nela, na distância miraculosa, nasce a tristeza, preço interior desse génio eléctrico de marcar os outros, quando chega para saber como é" (Helder, 2001, pp. 170-171).

Esta fragmentação da narrativa encontra-se igualmente em outro texto de Os Passos em Volta, no texto "O Coelacanto", quando, a respeito do ictiologista "funcionário das finanças, casado, 54 anos" (Helder, 2001, p. 59) que parte à procura do animal, o narrador evoca "uma história que confunde as leis, embaraçando aquelas perspectivas em que um homem fornece em bloco de um potencial biográfico, e seu desenvolvimento" (Helder, 2001, p. 59). A "verdade biográfica" passa então a ser apresentada em blocos, concentrações de imagens, ou talvez "punti luminosi poundianos". Pois, a imagem-texto em H. Helder é pensada como luz. Com a prudência necessária, talvez pudéssemos simplesmente afirmar que a imagem dá forma às vozes poéticas presentes na sua obra. $\mathrm{E}$ não se trata aqui de uma simples metáfora, pois, se lemos com cuidado a nota que acompanha Ou o poema contínuo, percebemos claramente que o poeta parte da imagem, da luz, para atingir o canto:

O poema contínuo parecia não exigir a escusa das partes que não eram punti luminosi poundianos, ou núcleos de energia assegurando uma continuidade imediatamente sensível. O livro de agora pretende aceitar a excusa e (...) estabelecer apenas as notas impreteríveis para que da pauta se erga a música (...). (H. Helder, 2001, pp. 5-6; grifos nossos)

A expressão, punti luminosi de Ezra Pound, recuperada por Herberto Helder, ${ }^{5}$ descreve os textos da obra que foram capazes de atirar os olhos dos leitores, rasurando os textos que os contornam, justifica o aparelho editorial do poema contínuo.

A técnica de concentração do autorretrato helderiano pode atingir igualmente a construção poética e, em "Retratíssimo ou narração de um homem depois de Maio", a

\footnotetext{
${ }^{5}$ A expressão é utilizada na entrevista de 1959 dada por E. Pound a Haroldo de Campos na Itália e publicada no Brasil em 1960 que se intitua "I punti luminosi".
} 
utilização de mots-valises permite a representação do movimento, sem a necessidade de recorrer à narratividade. $\mathrm{O}$ retrato agora é veloz e pura imagem:

Retratoblíquo sentado.

Retratimensamente de/lado, no/acto

conceptual de/ver quantos vivos quantos

dando folhas sobre os mortos de topázio.

Mãosagora, veloz rosto, visão pura. (Helder, 2014, p. 179)

A assinatura final, "vai morrer imensamente (ass)assinado", rasura, ela também, a narratividade e concentra a imagem-texto helderiana.

\section{Montagem}

Assim, a técnica cinematográfica da montagem também rege a poética helderiana que almeja alcançar "uma continuidade imediatamente sensível". Entretanto, esta imagemmontagem perturba a progressão da narração que se torna uma concentração de imagensintervalo, expressão utilizada por Georges Didi-Huberman e que seria a imagem que fixa:

[um] "momento transitório, pois: tal qual um nó — literalmente — de toda imagem e do problema estético que ela vem a resolver. O momento-intervalo, o momento que não é nem a postura de anterior, nem a posterior, o momento de não-estase que se lembra e que antecipa as estases passadas e futuras (...). ${ }^{\prime 6}$ (Didi-Huberman, 2002, p. 208)

A imagem-intervalo no universo helderiano assemelha-se àquela do peixe que se muda da cor vermelha para a cor preta do texto "Retrato em Movimento". Lembremos apenas que o texto abre o primeiro número dos Cadernos de Poesia Experimental em 1964 e foi depois inserido no livro Os Passos em Volta com o título "Teoria das Cores". No fim, lemos:

Ao meditar sobre as razões da mudança exactamente quando assentava na sua fidelidade, o pintor supôs que o peixe, efectuando um número de mágica, mostrava que existia apenas uma lei abrangendo tanto o mundo das coisas, como o da imaginação. Era a lei da metamorfose.

Compreendida esta espécie de fidelidade, o artista pintou um peixe amarelo. (Helder, 2001, pp. 21-22)

O pintor resolve, pelo uso da cor amarela, as diversas negociações operadas nas representações e sobretudo na representação do peixe. Assim, a cor amarela soluciona o problema estético entre o pintor e o seu modelo, mas também, através da frase "Era a lei da metamorfose", o poeta acolhe o público nesta negociação, que compreende, junto com o pintor, a nova teoria mimética deste universo. Porém, a negociação é resolvida por uma cor específica, o amarelo, cor recorrente na evocação do ouro, elemento alquímico, como também na passagem do tempo, como no conto "Equação", do mesmo Os Passos em Volta.

O que era um convite à participação do leitor na "lei da metamorfose" torna-se uma imposição autoral. A figura do autor forte esboça uma linha de leitura da obra perpassada por uma série de autorretratos que nos levariam a ler a poesia helderiana como um poema "não em língua plana mas em língua plena" (Helder, 2014, p. 749). Plena já que

\footnotetext{
6 "Moment 'transitoire', donc: tel est le nœud — c'est le cas de le dire — de toute image et du problème esthétique qu'elle résoud. Le moment-intervalle, le moment qui n'est la posture d'avant, ni celle d'après, le moment de non-stase qui se souvient et qui anticipe les stases passées et à l'avenir (...)" (Didi-Huberman, 2002, p. 208).
} 
construída de montagens de imagens-intervalo que se expandem, como o é o poema, para H. Helder, já que este nasce na "ferocidade e gosto" (Helder, 2014, p. 28).

Um dos últimos autorretratos de Herberto Helder foi publicado postumamente, em Letra Aberta (2016), ou seja, na recolha oriunda da seleção dos poemas feita por Olga Lima e que abre com uma fotografia do poeta realizada por Alfredo Cunha. A imagem de Herberto Helder, ressurgida depois de longa ausência, é agora a de um homem de idade avançada, olhar direto, mas ao mesmo tempo gentil. Um autorretrato poético encerra a recolha dialogando com a fotografia que abre o volume:

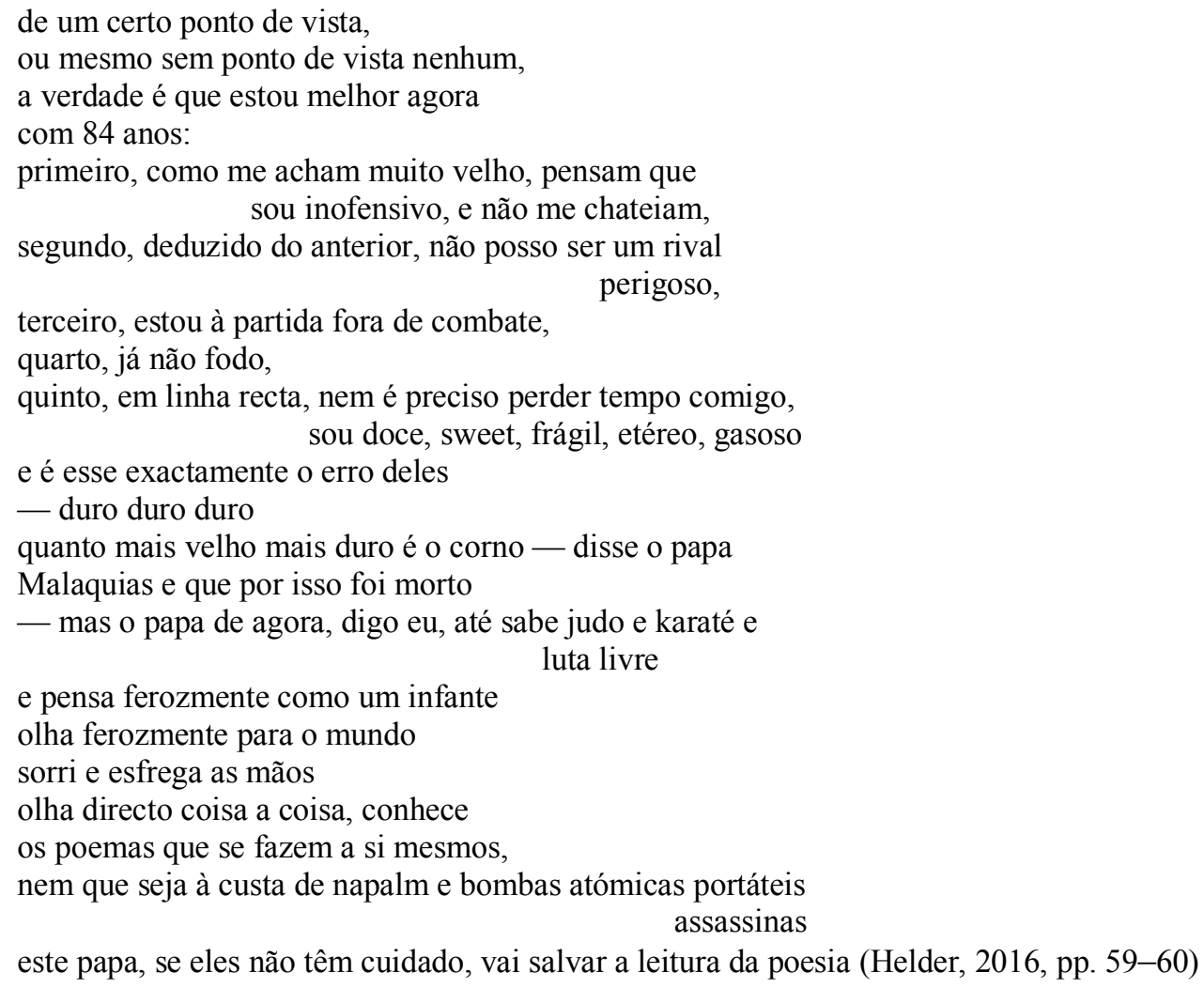

A intimidade biográfica do volume - a homenagem da sua companheira de vida, a reprodução de rascunhos e de documentos de trabalho, a fotografia - contrasta, "de um certo ponto de vista", com o estrondoso silêncio helderiano, e entretanto, reforça a tentação biográfica, que, desde o Apresentação do Rosto, atravessa a obra.

O poema supracitado inicia-se com a destruição de um dos três pontos de negociação da representação enunciada na teoria das cores (artista, modelo e público), ou seja, "o ponto de vista" dos outros é rasurado já que a posição "melhor agora", mesmo com 84 anos, impõe-se como verdade absoluta. Porém, logo após, o olhar do outro retorna nas expressões "como me acham muito velho", "pensam que sou inofensivo", para ser novamente negado pela dureza da pedra, dureza e resistência características da obra já enunciada em Lugar: "Sou fechado/ como uma pedra pedríssima" (Helder, 2014, p. 128).

O retrato continua então como um jogo de espelhos com a figura de um papa, o último segundo a profecia de Malaquias. A força da juventude aparece transladada para a imagem no espelho. O outro, o Papa, funciona aqui como possibilidade de julgamento e também como ponto de partida da enumeração de armas utilizadas para o terror: napalm, bomba atómica, etc. Michel Beaujour lembra que este gênero não deixa de ser, mesmo que como imagem inversa, speculum, ou seja enciclopédia, e que neste jogo “(...) o Outro (Inconsciente, amigo morto, leitor ou Deus) é o juiz e a garantia daquilo que o escritor 
reúne e espalha no seu autorretrato" (Beaujour, 1980,p. 36). ${ }^{7} \mathrm{O}$ autorretrato aparece assim como imagens fragmentadas, uma montagem de "pontos de vista" — "acham", "digo eu", etc... - que retrabalha centros temáticos da obra helderiana, ou melhor, "os automatismos da sua arte" (Arrase, 2006, p. 11). ${ }^{8}$ A expressão de Roland Barthes é evocada por Daniel Arasse, quando ele analisa a expressão da moda entre os artista florentinos do século XV, OGNI DIPINTORE DIPINGE SE, "Todo pintor pinta-se". O autorretrato também transparece claramente no retrato, já evocado anteriormente, da "catorzinha". A passagem entre o eu e a aparição, a aparecida, expressão que oscila entre o nome e o fenômeno, leva o poeta a retratar este corpo sempre utilizando como espelho, ou lente, o abismo entre o tempo do velho poeta com setenta e sete e a "beleza incompreensível". Voltamos a citar o poema:

quadris onde a luz é elástica ou se rasga,

luz que salta do cabelo,

joelhos, púbis, umbigo,

auréolas dos mamilos,

boca,

amo-te com dom e susto,

eles dizem que a beleza perdeu a aura, e eu não percebo, creio

que é um tema geral da crítica académica: dessacralização, etc., mas

tenho tão pouco tempo, eis o que penso: (Helder, 2014, p. 549)

O enumerar das partes do corpo da pequena não configura em si um retrato, mas é o olhar, a projeção entre o dom e o susto que cria a imagem aurática:

e a beleza é incompreensível,

é terrível, já se sabia pelo menos desde o Velho Testamento,

a beleza quando avança terrível como um exército,

e eu trabalho quanto posso pela sua violência,

e tu, catorze, floral toda aberta e externa, arrebata-me nos meus setenta e sete vezes êrro. (Helder, 2014, p. 549)

Mais uma vez, o espaço projeta-se numa montagem de referências, o speculum do mundo, que vai desde o Velho Testamento à metamorfose do corpo feminino e jovem em flor.

A idade biográfica (setenta e sete) nos leva mais uma vez a reconhecer "blocos biográficos" que vão, pouco a pouco, recriando um efeito de série, com as suas repetições e diferenças. O texto em prosa que abre Servidões reitera esta tentação de uma obra biográfica, e a relaciona com imagens vorazes, que se alimentam do traço biográfico:

Compreendi então: cumprira-se aquilo que eu sempre desejara — uma vida subtil, unida e invisível que o fogo celular das imagens devorava. Era uma vida que absorvera o mundo e o abandonara depois, abandonara a sua realidade fragmentária. Era compacta e limpa. Gramatical. (Helder, 2014, p. 626; grifos nossos)

A montagem é assim também a ferocidade, alimentação de imagens que tendem a destruição para a formação de uma nova imagem. A imagem da vida "gramatical" querse assim composta por imagens oriundas de uma força celular, ou fundamental, se lembramos do texto "Estilo" dos Passos em Volta.

\footnotetext{
7 “Mais l'Autre (Inconscient, ami mort, lecteur ou Dieu) reste le juge et garant de ce que l'écrivain rassemble et distribue dans son autoportrait, qui est au demeurant une sorte d'encyclopédie". [Traduçao nossa.]

8 “(...) le style est constitué par 'des images, un débit, un lexique naissant du corps et du passé de l'écrivain et devenant peu à peu les automatismes mêmes de son art”’. [Tradução nossa.]
} 
O elemento alquímico da transformação, o fogo, evoca o título anterior a faca não corta o fogo, recolha que já tem como estrutura a resistência ao tempo, apesar da idade avançada. Assim, se a imagem persiste no fogo que a devora, e contudo nos dá a ver outra imagem, sobreposta, em bloco na memória do leitor. Ela passa a representar diferentes "idades de poesia". G. Didi-Huberman, analisando a obra de Blossfeldt, lembra-nos da "confusão" da montagem das imagens de plantas em crescimento e ele, evocando Walter Benjamin, conclui: "Pois elas [as imagens originais] nos revelam o tempo das alterações, da perturbação: o movimento turbilhonante que elas produzem no tecido contínuo dos aspetos naturais, este movimento é próprio sintoma" (Didi-Huberman, 2000, p. 147). ${ }^{9}$

Para H. Helder, o cinema, através da montagem, permite precisamente criar, através da superposição/justaposição, a imagem-intervalo, ou sintoma, da qual nos fala o crítico francês: "O cinema extrai da pintura a acção latente de deslocação, de percurso" (Helder, 2006, p.142). Mais uma vez, ele revela a importância da "lei da metamorfose" que rege tanto a realidade - a "verdade biográfica" - como a sua representação.

A montagem cria igualmente a possibilidade de um jogo de espelhos entre o retratado e o artista. No retrato da jovem projeta-se a velhice do poeta. No esquecimento do fogo, ilumina-se a memória. No texto "(memória, montagem)" de Photomaton \& Vox, H. Helder afirma: "Eu penso que a memória entra pelos olhos" (Helder, 2006, p. 138) e, em "Equação" de Os Passos em Volta, a luz da fotografia da velha avó molda o eu através de violentos golpes, como se esculpisse nele uma memória: "Bate-me em cheio. Bate em mim, junto à cama, em mim que assisto a um tempo bem actual, à fluente e temível demonstração do corpo que continuou o movimento. Para diante, para diante. Rompendo as ficções do estatismo, o mito incomportável das fotografias" (Helder, 2001, p.131).

Silvina Rodrigues Lopes já havia atentado para a posição dominante dos golpes de martelo — ou de luz — na obra do poeta: "É evidente que nos golpes de martelo dos poemas de Herberto Helder ressoam os golpes nietzscheanos do pensamento, (...) onde se fala da necessidade de a golpes de martelo procurar na pedra uma imagem que seja 'a imagem das minhas imagens"” (Lopes, 2003, p. 88). A imagem do poeta, seu retrato, passa então pela articulação entre a imagem e a memória obtida pela força ou pela aparição do sublime - como na "catorzinha". Em Photomaton \& Vox, o sublime parece ser designado pela surpresa e pelo seu caráter onírico: "O passado, a memória, a experiência constituem esse fundo de irrealidade que, semelhante a um feixe luminoso, aclara este momento de agora, revela como ele é cheio de surpresas, como já se destina à memória e é já essa incontrolável gramática sonhadora" (Helder, 2006, p. 22).

A memória é assim a montagem de blocos luminosos, imagens sintomáticas que revelam traços biográficos não do poeta, mais da própria obra helderiana. Não sem ironia, em $A$ Morte sem Mestre, o poeta negará a sua imagem no espelho, lembrando que a imagem é feita de "papel e à esferográfica" (Helder, 2014, p. 727). Mais uma vez a imagem estática no tempo do retrato é ultrapassada:

e só agora penso:

porque é que nunca me olho quando passo defronte de mim mesmo?

para ver quão pouca luz tenho dentro?

ou o soluço atravessado no rosto velho e furioso,

agora que penso e vejo mesmo sem espelho? (Helder, 2014, p. 719)

\footnotetext{
9 “Car ce dont elles témoignent est le temps de l'altération, de la perturbation: le mouvement tourbillonnaire qu'elles produisent dans le tissu continu des aspects naturels, ce mouvement est celui-là même du symptôme." [Tradução nossa.]
} 
O autorretrato, em abismo e às avessas, recria o cogito cartesiano, deslocando-o da razão para o sensível, a visão.

Os múltiplos retratos helderianos são assim um estilo que leva o autor ao conhecimento da poesia. Oriundos da intersecção entre técnicas retóricas e artísticas, produzem tanto o canto quanto a imagem de um universo singular e pessoalíssimo, no qual o sensível e a alucinação - muitas vezes ligada, como vimos, a animalização do sujeito - , a memória e o esquecimento, o eu e o outro se confundem numa imagem feita de interferências, cortes, fragmentações, mas também continuidades, justaposições e iluminações.

\section{REFERÊNCIAS}

Arasse, D. (2006). Le sujet dans le tableau. Paris: Champs arts.

Didi-Huberman, G. (2000). Devant le temps. Paris: Les Éditions de Minuit.

(2002). L'image survivante: Histoire de l'art et temps des fantômes selon Aby Warburg. Paris: Les Éditions de Minuit.

Helder, H. (2001). Os passos em volta. Lisboa: Assírio \& Alvim. (2006). Photomaton \& Vox. Lisboa: Assírio \& Alvim. (2014). Poemas completos. Porto: Porto Editora. (2016). Letra aberta. Porto: Porto Editora.

Lopes, S. R. (2003). A inocência do devir, Lisboa: Edições Vendaval.

Maffei, L. (2009). (77 x 14) + 2009: 38 د beleza (herbertequação). Diacrítica, 23,113-128.

Thomas, Y. (2001). L'aveu, de la parole au corps (Rome, Ve siècle av. J.-C - Ive siècle apr. J.C.) (17-56). In R. Dulong (dir.), L'aveu: Histoire, sociologie, philosophie. Paris: PUF.

Todorov, T. (2004). L'Éloge de l'individu: Essai sur la peinture flamande de la Renaissance. Paris: Éditions Adam Biro. 
